\title{
- La gobernanza regional en educación: El caso de la Unión Europea y sus implicaciones para América Latina Esthela Alfonsina Andrade Ortega*
}

\section{Introducción}

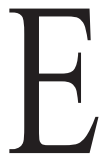

1 artículo analiza las implicaciones que ha tenido para América Latina el Proceso de Bolonia, en el contexto de la gobernanza regional en educación. Por tanto, se considera necesario para iniciar, definir la gobernanza como "un cambio en lo que los Estados son y lo que pueden hacer como nuevas formas de tomar decisiones y actuar sobre los problemas colectivos que desarrollan". ${ }^{1}$ Es decir, es una forma de coordinar acciones entre actores estatales o no, para resolver o enfrentar diferentes problemáticas, sean estas globales o regionales. De esta manera, el manejo de los problemas globales, cada vez más complejos, no puede estar limitado a lo que pueden hacer, o las políticas que pueden implantar los gobiernos nacionales, por lo cual, cada día, son más comunes las iniciativas de cooperación en integración regional entre países. A nivel de América Latina, "la integración regional hoy representa un conglomerado de proyectos que no solo aborda temas comerciales, sino también políticos y sociales, articulados alrededor de nuevos objetivos y prácticas, basados en solidaridad y autonomía". ${ }^{2}$

A pesar de que estos acuerdos tienen como objetivo la cooperación entre los países, para enfrentar o solucionar los problemas globales y regionales, hay críticas muy fuertes a estas dinámicas. En el caso de la implantación del Proceso de Bolonia en América Latina, se lo ha acusado de limitar la posi-

\footnotetext{
Doctoranda en Estudios Latinoamericanos, Universidad Andina Simón Bolívar, Sede Ecuador. Profesora, Pontificia Universidad Católica del Ecuador, Sede Ibarra; ‘eaandrade1@pucesi.edu.ec〉.

1. Timothy J. Sinclair, Global Governance (Cambridge: Polity Press, 2012), 197.

2. Pia Riggirozzi, "UNASUR: Construcción de una diplomacia regional en materia de salud a través de políticas sociales", Estudios Internacionales 47, No. 181 (2015): 29-50.
} 
bilidad de las universidades de constituir un proyecto propio que promueva la creatividad y el pensamiento crítico en la diversidad, para convertirse en meras proveedoras de mano de obra calificada, muy dependiente de los requerimientos del mercado; además de que, este intento de homogenización, afecta la pertinencia institucional.

\section{El Proceso de Bolonia}

Los orígenes de este proceso los encontramos en la Carta Magna de las Universidades (1988), ${ }^{3}$ en la que, los rectores de varias universidades europeas planteaban la necesidad de reformar la universidad para abrirse a las necesidades del mundo contemporáneo, en un marco de independencia científica y social, y de respeto entre las universidades y los poderes públicos. Para ello, se requería la supresión de las fronteras que las separaban, de manera que se de una colaboración efectiva entre todas ellas.

Incentivados por los avances dados por el proceso de integración europeo, la Declaración de la Sorbona (1998), firmada por los ministros de educación de cuatro países, abre las puertas a la armonización del diseño de educación superior europeo, por lo que es "reconocida como el inicio del proceso más reciente e integral para llegar a un acuerdo entre países europeos en el campo de la educación superior". ${ }^{4}$ En ella, se solicitaba al resto de países europeos su apoyo e inserción en esta importante iniciativa para el mejoramiento del sistema universitario europeo.

La Declaración de Bolonia, firmada por los ministros de educación de 29 países, en la ciudad que le da su nombre, el 25 de mayo de 1999, marcó un hito en la educación superior de Europa, pues permitió a los países europeos sentar las bases para la construcción de un Espacio Europeo de Educación Superior para el año 2010; armonizando los sistemas universitarios de los países miembros para fomentar y facilitar la movilidad estudiantil, docente y profesional, en vista de que la Unión Europea (UE) no tiene competencias respecto a la educación superior. Esta declaración buscaba hacer atractivo el espacio europeo de educación, tanto para sus miembros como para terceros.

3. Con motivo del IX centenario de la Universidad de Bolonia.

4. Adrián Garay Sánchez, "Los Acuerdos de Bolonia; desafíos y respuestas por parte de los sistemas de educación superior e instituciones en Latinoamérica", Universidades, No. 37 (2008): $17-36$. 
Su operatividad requería diseñar un patrón que pueda ser implantado por todas las universidades, pero sobre todo, que no presentara mayores problemas de aplicabilidad. Por estos motivos, se estableció la necesidad de determinar "competencias" y "resultados de aprendizaje" más que contenidos académicos, para las diferentes carreras, de manera que los perfiles profesionales de los graduados en cada una de ellas pudieran homogeneizarse.

Estas competencias se refieren a los conocimientos, destrezas y habilidades mínimas que deben adquirir los estudiantes durante su formación profesional, más no a los contenidos de las diferentes carreras. La concepción de competencia se articula al campo profesional y laboral del individuo; en otras palabras, se refiere al "saber hacer" de la profesión. Se consideró que establecer este sistema de competencias, al que se lo denominó Proyecto Tuning, era mucho más realista que "establecer e implantar contenidos académicos únicos en todas las universidades y carreras". ${ }^{5}$ Este proyecto se consolidó en Europa en el año 2001.

Conforme se iba implantando el aprendizaje por competencias en las universidades, comenzaron a surgir diferentes posiciones respecto a las ventajas que suponía. Ha predominado una posición contraria a esta reforma porque considera a la educación como mercancía (servicio educativo) y a los graduados como productos donde la lógica neoliberal de la competencia, productividad y eficiencia económica es la que se impone en las políticas institucionales.

Autores como Montero ${ }^{6}$ y Diez, ${ }^{7}$ manifiestan que este proceso constituyó la oportunidad para que las universidades europeas "pudieran establecer, por un lado, un conjunto de reformas, mejorar la calidad de la educación impartida, pero a la vez adaptarse a los requerimientos del proceso de globalización y a la nueva realidad social que este involucra y que es la 'Sociedad del Conocimiento", 8 pero así mismo llevaba a la educación superior europea a inscri-

5. Hugo Aboites, "La educación superior latinoamericana y el proceso de Bolonia: de la comercialización al proyecto Tuning de competencias", Cultura y representaciones sociales 5, No. 9 (2010).

6. Marisa Montero Curiel, "El Proceso de Bolonia y las nuevas competencias", Tejuelo, No. 9 (2010): 19-37.

7. Enrique Javier Díez Gutiérrez, "El capitalismo académico y el plan Bolonia", Eikasia: Revista de Filosofía, No. 23 (2009).

8. Este término se refiere a "una sociedad caracterizada por una estructura económica y social, en la que el conocimiento ha substituido al trabajo, a las materias primas y al capital como fuente más importante de la productividad, crecimiento y desigualdades sociales." Montero, "El Proceso de Bolonia y las nuevas competencias", 21, 
birse en una lógica de mercado en detrimento de su misión social formadora de pensamiento crítico y ciudadanía comprometida y responsable.

Otra de las críticas que se han hecho, es la referida al financiamiento que requieren los países y las universidades para armonizarse al proceso de Bolonia. ${ }^{9}$ Se considera preocupante que los costos del proyecto hayan recaído en los bolsillos de los estudiantes, quienes deben pagar más para terminar su formación y adquirir un título que les permita insertarse en los empleos mejor remunerados del mercado laboral. También, se plantea que el modelo no responde a las necesidades estudiantiles, pues el sistema de créditos involucra que un estudiante, además de dinero, deberá invertir más horas para asistir a clases, realizar trabajos y hacer prácticas, es decir únicamente puede ser un estudiante a tiempo completo, lo que limitaría las posibilidades de aquellos que pertenecen a las clases sociales más desfavorecidas y cuya única oportunidad de acceder a la universidad es compaginar estudios y trabajo.

\section{Bolonia y América Latina}

Para De Lombaerde y Söderbaum, luego de la Segunda Guerra Mundial, Europa ha dominado el campo para el desarrollo conceptual, teórico y empírico sobre acuerdos regionales e integración. Así es como las teorías se desarrollan a menudo para y desde la experiencia europea y luego con frecuencia se “exportan” a todo el mundo, y América Latina no es la excepción. ${ }^{10}$ Más allá de los acuerdos económicos, comerciales o de seguridad que han dominado el estudio de la gobernanza regional y global, la educación superior clarifica perfectamente esta exportación de experiencias regionales desde Europa hacia América Latina. El colonialismo cultural continúa y se proyecta. Así, faltando pocos meses para iniciar el siglo XXI, el recién estrenado modelo europeo de educación superior se trasladó sin mayores modificaciones a América Latina.

Para nuestros países, trasladar la experiencia europea en educación no representaba una práctica nueva, sino una especie de continuidad a una dinámica que se había dado desde el inicio del contacto con Europa. Durante la

9. Enrique Javier Díez Gutiérrez, "Bolonia: ¿racionalización de la educación universitaria o modelo neoliberal?", Aula de Innovación Educativa, No. 186 (2009).

10. Philippe De Lombaerde y Frederik Söderbaum, Regionalism, Volume One: 1940s-1960s Classical Regional Integration (London: Sage Publications, 2013). 
conquista de América, las instituciones universitarias que se fundaron en este continente funcionaban bajo los modelos de Salamanca o Alcalá. El proceso independentista tampoco marcó una ruptura con los modelos traídos de Europa. La universidad colonial fue sustituida por el modelo napoleónico que ponía particular atención en las profesiones en un andarivel diferente al de la investigación científica. En estos años y hasta los primeros años de la República, la educación se encontró muy influenciada por el pensamiento ilustrado que, en el caso de los países andinos, tuvo como promotor a Simón Rodríguez quien consideraba que educar era básico para conformar los nacientes Estados, se debía educar para la libertad y la igualdad, ya que solo así se puede superar la ignorancia.

Para el caso ecuatoriano, podemos observar que varios de los presidentes insertaron modelos de educación que habían conocido en Europa e, incluso, trajeron misiones académicas. Por ejemplo, el modelo de escuela que planteaba Rocafuerte era el Lancasteriano, el que había conocido cuando se encontraba en Inglaterra. ${ }^{11}$ García Moreno trajo al Ecuador diferentes órdenes religiosas y misiones pedagógicas europeas, entre las que hay que resaltar a los jesuitas alemanes, en cuyas manos puso el manejo y funcionamiento de la Escuela Politécnica Nacional. También Eloy Alfaro trajo al país varias misiones pedagógicas desde Europa que le permitieron afianzar su proyecto político y educativo, fundamentado en el laicismo para separar los ámbitos ideológicos de la iglesia y el Estado.

En los años 90, por la complejidad de los problemas regionales, comenzaron a surgir en América Latina "nuevas formas de cooperación transnacional en el ámbito de la vigilancia de la salud y la migración laboral, así como en áreas específicas consideradas claves para impulsar la competitividad del mercado, como la educación superior y la inversión extranjera". ${ }^{12} \mathrm{Al}$ mismo tiempo, el incremento de acuerdos comerciales entre los diferentes países oca-

11. El modelo Lancasteriano estaba basado en un sistema de recompensas y castigos. Los alumnos permanecían en la escuela alrededor de 7 horas diarias. Existía un solo maestro para una gran cantidad de niños (200 o más) ya que de los alumnos más avanzados apoyaban al maestro en la enseñanza de los menores. De esta manera, se podían reducir los costos que la educación implicaba.

12. Riggirozzi, "UNASUR: Construcción de una diplomacia regional en materia de salud a través de políticas sociales". 
siona la necesidad de insertarse favorablemente en una economía mundial que prioriza el conocimiento y la innovación.

Por tal motivo, se incrementó la demanda de servicios educativos para la formación de profesionales en diferentes áreas, fomentada, entre otras, por la lógica mercantil que promovía el Consenso de Washington, incentivando la creación de nuevas universidades y la ampliación de su oferta académica en muchos de los países latinoamericanos. Europa también había incrementado la oferta de servicios educativos, principalmente de posgrados hacia los países latinoamericanos, lo que impulsó la cooperación de estas dos regiones en áreas no económicas.

Varias instituciones ofertaron títulos de posgrado, tanto de manera presencial como a distancia, dando facilidades de pago y acceso a becas, lo que benefició a los profesionales latinoamericanos. Uno de los países con mayor oferta educativa hacia América Latina fue España, cuyas iniciativas emanaron principalmente a través de uno de los grupos financieros más importantes, el Grupo Santander, que creó la Fundación Universia, a través de la cual facilitaba la movilidad y ofertaba becas y apoyos financieros, tanto a profesores como a estudiantes.

En este contexto, surge desde Europa el interés de trasplantar hacia América Latina el proyecto surgido en Bolonia. Esta iniciativa tuvo apoyo por parte de varios países de América Latina, entre otras cosas, porque en aquellos años "la globalización europea era vista como una fuerza algo menos atemorizante que la de Estados Unidos, más comprensible y humanitaria que la de los asiáticos y más acorde a nuestra idiosincrasia y costumbres que la de los australianos". ${ }^{13}$ En la Cumbre de Río de Janeiro, se expresó la voluntad de estrechar los lazos de colaboración con Europa en educación superior. Esto marca el inicio de la creación del Espacio Común de Educación Superior de la Unión Europea, América Latina y el Caribe (ALCUE) en el año 1999. El objetivo de este espacio es la promoción de iniciativas y acciones que:

fomenten y faciliten el intercambio y la circulación de estudiantes, profesores, investigadores, personal técnico y de gestión de los sistemas de educación superior, promoviendo la interacción de las instituciones de educación superior, universidades y otros;

13. René Bugarín Olvera, "Educación Superior en América Latina y el Proceso de Bolonia: Alcances y Desafíos", Revista Mexicana de Orientación Educativa, No. 16 (2009): 50-8. 
difundir información, promover la discusión, especialmente las relativas a la educación superior y puede contribuir a la mejora de la calidad de la educación superior en los países de la Unión Europea, América Latina y el Caribe. ${ }^{14}$

Para el año 2002, con la consolidación del Proyecto Tuning en Europa, los países miembros de ALCUE impulsan las aprobaciones en los diferentes organismos europeos para adoptar la propuesta europea, la misma que pasaría a llamarse Proyecto Tuning-América Latina ${ }^{15}$ Lo que enfatizaba este proyecto era "afinar las estructuras educativas de América Latina, iniciando un debate cuya meta es identificar e intercambiar información y mejorar la colaboración entre las instituciones de educación superior para el desarrollo de la calidad, efectividad y transparencia". ${ }^{16}$ Se esperaba que no solo se pudieran homologar las titulaciones, se incentivara la movilidad estudiantil o se establecieran proyectos conjuntos y otros, sino que también se pudiera mejorar la calidad de las instituciones de las universidades latinoamericanas; calidad que, con la proliferación de instituciones de educación superior en toda América Latina, se encontraba en entredicho.

Esta iniciativa fue presentada y aprobada a la Comisión Europea en el año 2003. En el año 2004, entra en vigencia y es implantada sin mayores modificaciones en América Latina. Se argumentó ${ }^{17}$ que esta coordinación de políticas en educación superior surge porque la aspiración de una alta competitividad y compatibilidad de la educación superior no es únicamente una preocupación europea sino una preocupación mundial.

La implantación de Bolonia en América Latina presenta algunas particularidades que deben señalarse. Así, la iniciativa no surge desde Latinoamérica sino desde Europa; la mitad de quienes lo trabajaron eran europeos y los latinoamericanos que formaban parte del mismo no constituyeron una verdadera representación del conjunto de universidades, por lo cual "simplemente se asumió que lo que era bueno para Europa lo sería también para América Latina”. ${ }^{18}$

14. ALCUE, ALCUE Common Area of Higher Education, 2011, 〈www.alcue.net〉.

15. Aboites, "La educación superior latinoamericana y el proceso de Bolonia: de la comercialización al proyecto Tuning de competencias", 132.

16. Garay Sánchez, "Los Acuerdos de Bolonia; desafíos y respuestas por parte de los sistemas de educación superior e instituciones en Latinoamérica", 4.

17. Según consta en la página web del Proyecto Tuning América Latina.

18. Aboites, "La educación superior latinoamericana y el proceso de Bolonia: de la comercialización al proyecto Tuning de competencias", 134. 
Cómo señala Acharya, se asignaron "recetas internacionales que no tienen en cuenta las 'normas que están profundamente arraigadas en otros tipos de entidades sociales regionales, nacionales, subnacionales y grupos', estableciéndose una dicotomía implícita entre las buenas normas globales o universales y las malas normas regionales o locales". ${ }^{19}$

No se tomaron en cuenta las particularidades de las diferentes universidades de Latinoamérica y tampoco de sus países, su diversidad cultural e identidad nacional, los mismos que presentan una dinámica diferente a la que tenía Europa el momento del establecimiento del Espacio Europeo de Educación Superior. Pues, "a diferencia de lo que ocurre en la vieja Europa, en América Latina no hay un espacio común ni político, ni económico, ni monetario, ni menos del conocimiento al cual apelar", ${ }^{20}$ por lo cual la implantación de esta iniciativa podía no dar los resultados deseados.

También implicó no solo el establecimiento de un modelo educativo basado en competencias, sino también "cambios en los modelos de financiamiento, exigencia de eficiencia a través de la implantación de sistemas evaluativos y presiones por relaciones más estrechas con el sector productivo". ${ }^{21}$

Por tal motivo, este proyecto ha sido criticado por tener una visión muy reduccionista de la educación, que no permite la formación de profesionales con una visión amplia y crítica, sino que, como dice Aboites, crea profesionales "de manual" sin formación ciudadana. A través de este, pudo consolidarse en América Latina el capitalismo académico ${ }^{22}$ que tiene un corte ideológico neoliberal, que mira a la educación (especialmente universitaria) no como un derecho sino como un mero servicio mercantil. Para clarificar esto, podemos observar que los modelos de evaluación de la calidad de las universidades y carreras tienen

19. Amitav Acharya, "Comparative Regionalism: A Field Whose Time has Come?", The International Spectator: Italian Journal of International Affairs 47, No. 1 (2012).

20. José Joaquín Brunner, "El proceso de Bolonia en el horizonte latinoamericano: límites y posibilidades", Revista de Educación, No. Extraordinario (2008): 119-45.

21. Marcela Mollis, comp. Las Universidades en América Latina: ¿Reformadas o Alteradas? La cosmética del poder financiero (Buenos Aires: Colección Grupos de Trabajo de CLACSO, 2003).

22. Lo que designamos con el nombre de "capitalismo académico en la nueva economía es un sistema que lleva a las universidades a vincularse con el mercado y los comportamientos propios del mercado". Gary Rhoades y Sheila Slaughter, "Capitalismo académico: en la nueva economía: Retos y decisiones”, Pasajes: Revista de pensamiento contemporáneo, No.33 (2010): 43-59. 
su origen en la evaluación de los estándares de calidad de las industrias y buscan cumplir objetivos similares a los que cumplen las normas ISO.

La construcción del espacio de educación superior entre América Latina y Europa, a pesar de los avances que ha tenido en estos quince años de existencia, aún no termina de fortalecerse $y$, por tanto, aún no se puede efectuar una revisión más amplia de sus éxitos y/o fracasos. Se han realizado, sin embargo, algunas actividades como la I Conferencia Ministerial de los países de la Unión Europea, de América Latina y el Caribe sobre Enseñanza Superior, en el año 2000 en París; la II Conferencia de Ministros responsables de Educación Superior en Guadalajara, México, en 2005; la Primera Cumbre Académica CELAC-UE en Santiago de Chile, en 2013; la Segunda Cumbre Académica CELAC-UE en Bruselas en 2015 y la Tercera Cumbre Académica CELAC-UE llevada a cabo en El Salvador en 2017.

Entre los objetivos que se han trazado con estas actividades, se encuentran no solo crear un espacio común de educación superior, sino también un espacio de conocimiento que conduzca a la integración de la educación superior con la investigación e innovación; para lo cual se requiere solicitar a los jefes de Estado crear las condiciones normativas y financieras para la consolidación de este espacio, así como promover la transformación de las instituciones de educación superior para facilitar la integración de los sistemas de investigación científica e innovación.

Con este sistema, centrado en la investigación, las universidades deben pasar de producir ciencia básica [...] para su publicación, a producir ciencia aplicada en colaboración con la industria para el desarrollo de patentes y, con ellas, de una nueva fuente de ingresos para la universidad. ${ }^{23}$ Así, se corre el peligro de que los grandes beneficiarios sean las transnacionales, pues podrían absorber mano de obra altamente calificada y económica, ante la imposibilidad de la mayoría de países latinoamericanos de captarla debido al limitado desarrollo industrial y tecnológico que los caracteriza.

Para finalizar, se debe manifestar que la dinámica de implantación del Proceso de Bolonia en América Latina ocasiona rupturas, enfrentamientos y polémicas entre la universidad, el Estado y la sociedad, así como entre quienes proponen continuar en el camino de ajustar la universidad únicamente a la

23. Rhoades y Slaughter, Capitalismo académico: en la nueva economía: Retos y decisiones”. 
lógica mercantil o retomar un camino más amplio y más crítico que enfatice en las particularidades culturales y de desarrollo de los países y regiones.

\section{Bibliografía}

Aboites, Hugo. "La educación superior latinoamericana y el proceso de Bolonia: de la comercialización al proyecto Tuning de competencias". Cultura y representaciones sociales 5, No. 9 (2010).

Acharya, Amitav. "Comparative Regionalism: A Field Whose Time has Come?". The International Spectator: Italian Journal of International Affairs 47, No. 1 (2012).

ALC UE. ALCUE Common Area of Higher Education, 2011. 〈www.alcue.net).

Brunner, José Joaquín. "El proceso de Bolonia en el horizonte latinoamericano: límites y posibilidades". Revista de Educación, No. Extraordinario (2008): 119-45.

Bugarín Olvera, René. "Educación Superior en América Latina y el Proceso de Bolonia: Alcances y Desafíos". Revista Mexicana de Orientación Educativa, No. 16 (2009): 50-8.

De Lombaerde, Philippe y Frederik Söderbaum. Regionalism, Volume One: 1940s-1960s Classical Regional Integration. London: Sage Publications, 2013.

Díez Gutiérrez, Enrique Javier. "El capitalismo académico y el plan Bolonia". Eikasia: Revista de Filosofía, No. 23 (2009).

"Bolonia: ¿racionalización de la educación universitaria o modelo neoliberal?". Aula de Innovación Educativa, No. 186 (2009).

Garay Sánchez, Adrián. "Los Acuerdos de Bolonia; desafíos y respuestas por parte de los sistemas de educación superior e instituciones en Latinoamérica". Universidades, No. 37 (2008): 17-36.

Mollis, Marcela, comp. Las Universidades en América Latina: ¿Reformadas o Alteradas?. La cosmética del poder financiero. Buenos Aires: Colección Grupos de Trabajo de CLACSO, 2003.

Montero Curiel, Marisa. "El Proceso de Bolonia y las nuevas competencias", Tejuelo, No. 9 (2010): 19-37.

Ornelas Delgado, Jaime. "Neoliberalismo y Capitalismo Académico". En Pablo Gentili, Gaudencio Frigotto, Roberto Leher, Florencia Stubrin, comp. Políticas de privatización, espacio público y educación en América Latina. Rosario: CLACSO, 2009.

Riggirozzi, Pia. "UNASUR: Construcción de una diplomacia regional en materia de salud a través de políticas sociales". Estudios Internacionales 47, No. 181 (2015): 29-50.

Rhoades, Gary y Sheila Slaughter. "Capitalismo académico: en la nueva economía: Retos y decisiones". Pasajes: Revista de pensamiento contemporáneo, No.33 (2010): 43-59.

Sinclair, Timothy J. Global Governance. Cambridge: Polity Press, 2012. 